\title{
Encontros e desencontros entre a saúde do homem, a promoção da paternidade participativa e a saúde sexual e reprodutiva na atenção básica
}

\section{| ${ }^{1}$ Cláudia Regina Ribeiro, ${ }^{2}$ Romeu Gomes, ${ }^{3}$ Martha Cristina Nunes Moreira |}

Resumo: Neste artigo, objetivamos problematizar três açôes desenvolvidas em unidades básicas de saúde de três municípios de regiões brasileiras distintas, voltadas para a saúde do homem, a promoção da paternidade participativa comprometida com o cuidado e a saúde sexual e reprodutiva. Trata-se de uma pesquisa qualitativa em que os dados foram construídos através de observaçôes e de entrevistas com 17 homens, usuários do sistema de saúde e envolvidos nessas açôes. $\mathrm{Na}$ análise dos dados, foram trazidos de forma especial os conceitos de gênero, masculinidades e integralidade; como metodologia de análise, lançamos mão da perspectiva hermenêutica-dialética. Dentre outros aspectos, concluímos que os homens percebem que as questôes de gênero ainda são impeditivos para essa inserção, assim como a organização do próprio sistema; e que as açôes analisadas se organizam de forma estanque e fragmentada, atuando sobre aspectos isolados da saúde masculina, não contemplando o princípio da integralidade e dificultando a promoção do vínculo desses homens ao sistema pela atenção primária.

> Palavras-chave: saúde do homem; paternidade; saúde sexual e reprodutiva; integralidade; gênero.

\author{
1 Pós-Doutora em Saúde da \\ Criança e da Mulher - Instituto \\ Fernandes Figueira/Fiocruz. \\ Doutora em Saúde Coletiva \\ - IMS/Uerj. Instituto de Saúde \\ Coletiva - ISC/UFF. \\ Endereço eletrônico: \\ 13cribeiro@gmail.com \\ ${ }^{2}$ Livre-docente em Psicologia/ \\ Uerj. Doutor em Saúde Pública \\ - Fiocruz. Pesquisador no \\ Instituto Fernandes Figueira - \\ Fiocruz. Endereço eletrônico: \\ romeu@iff.fiocruz.br \\ ${ }^{3}$ Doutora em Sociologia \\ - IUPERJ. Pesquisadora no \\ Instituto Fernandes Figueira - \\ Fiocruz. Endereço eletrônico: \\ moreira@iff.fiocruz.br
}

Recebido em: 23/07/2015 Aprovado em: 05/02/2016 
Os homens, em geral, não são socializados para cuidarem de si, nem para cuidar dos outros, sendo o cuidado comumente associado ao âmbito feminino (MEDRADO; LYRA; AZEVEDO, 2009; GOMES, 2008a; 2008b; 2010; COURTNEY, 2000). Esse modelo cultural compromete tanto a saúde dos homens quanto das mulheres, resultando na baixa procura pelas unidades de atenção primária. Eles costumam acessar os serviços de saúde pela atenção secundária ou terciária e quando já estão em estado avançado de adoecimento (GOMES ET AL., 2011; COUTO;GOMES et al., 2012)

Como afirmam Gomes (2012) e Toneli et al. (2011), as políticas públicas voltadas para os homens esbarram em questóes culturais para a sua implementação. Promover a reflexão destes, levando em conta as diferentes masculinidades, é um aspecto fundamental para o sucesso da Política Nacional de Atenção Integral à Saúde do Homem (PNAISH), incluindo ainda os profissionais de saúde nessa reflexão. Para Correa e Petchesky (1996), direitos reprodutivos são uma entre tantas estratégias que buscam equalizar as posiçôes de homens e mulheres na sociedade. No entanto, somente mulheres engravidam e há mais métodos contraceptivos voltados para elas. Para além das questões de gênero, outras diferenças se colocam por marcadores socioeconômicos, de raça, etnia, idade, orientação sexual, entre outros.

Ao associar a saúde sexual, a reprodutiva e a paternidade em ações de saúde, a PNAISH (BRASIL, 2008), inova na proposição da melhoria das condições de saúde do homem junto à necessidade de se considerar as questões de gênero. No entanto, historicamente, essas são demandas femininas, enquanto os homens, não raramente, tendem a escapar dessas responsabilidades (CARRARA; FARO; RUSSO, 2009).

Nesse cenário, desenhar ações voltadas para saúde do homem na atenção ao pré-natal pode ser um desafio. Pode também ser uma alternativa estratégica que articule as açóes de saúde sexual e reprodutiva e as que buscam incentivar uma paternidade participativa, aqui entendida como "aquela que subentende o cuidado e o envolvimento constante no cotidiano dos filhos - nos domínios da alimentação, higiene, lazer e educação" (SUTTER; BUCHER-MALUSCHKE, 2008). Tal definição implica estratégias para o envolvimento prazeroso dos homens na gravidez, parto, no cuidado com os filhos, bem como relacionamentos 
domésticos mais democráticos e equitativos (KEIJZER, 2003; RIBEIRO; GOMES; MOREIRA, 2015). Em relação à saúde sexual e reprodutiva, é importante ampliara instância de promoção de direitos equânimes e da atenção integral às necessidades de saúde, tanto femininas quanto masculinas (SCHRAIBER et al., 2005; COUTO; GOMES et al., 2012).

Há experiências, como as ações Pré-Natal Masculino, o Pré-Natal do Parceiro e as Unidades de Saúde Parceiras do Pai, que vêm sendo desenvolvidas em Foz do Iguaçu, Ribeirão Preto e Rio de Janeiro, respectivamente, que identificam o pré-natal como um momento-chave para a inclusão dos homens no sistema de saúde e vêm sendo apoiadas e estimuladas pelo Ministério da Saúde. No entanto, a produção científica acerca dos efeitos da participação masculina no pré-natal sobre a saúde do homem/pai é mais de caráter opinativo do que discussões apoiadas em pesquisas de campo. Nesse cenário, faz-se necessário compreender como os homens vêm percebendo o desenvolvimento das açôes que ensaiam a operacionalização dos princípios políticos sobre o seu envolvimento na saúde reprodutiva e sexual, bem como acerca da paternidade.

Objetivamos analisar os sentidos atribuídos por homens às ações de atenção à saúde voltadas para eles, evocando a tríade sexualidade, reprodução e paternidade. Potencializar a voz desses homens, os usuários das ações, é um passo fundamental para avançarmos na promoção da saúde masculina.

\section{Marcos teóricos}

Como marcos teóricos, apoiamo-nos nos estudos de gênero e seus desdobramentos nos estudos das masculinidades, sintonizando-os com a noção de integralidade em saúde.

Compreendemos o gênero como o que é referente às qualidades e distinções construídas social e culturalmente para homens e mulheres, tendo como ponto de partida o sexo com que nascemos. Trata-se de uma construção relacional, ou seja, constrói-se com e para o outro, que varia em cada momento histórico, sociedade e cultura, sendo ainda atravessado por relaçôes hierárquicas de poder em que os jogos de força e dominação se colocam, conferindo aos homens uma posição privilegiada socialmente (GOMES, 2008; KIMMEL, 1998; SCOTT, 1995; CONNELL, 1995). 
As relações de gênero não dizem respeito somente às relações entre mulheres e homens, mas incluem "dominação, marginalização e cumplicidade" (CONNELL, 1995, p. 189) também nas relações homens-homens e mulheres-mulheres, que não necessariamente passam pelo uso da força, mas pelos discursos, pelo consenso cultural, pela institucionalização e deslegitimação de formas alternativas. $\mathrm{Na}$ medida em que há masculinidades hegemônicas e subordinadas, o padrão para essas formas de ser masculino é definido temporal, cultural e geograficamente (CONNELL; MESSERSCHMIDT, 2013). O padrão hegemônico de masculinidade, em específico, e de gênero, em geral, interfere no autocuidado e no cuidar do outro, temas relacionados historicamente às mulheres.

Quanto à noção de integralidade, definimo-la como a forma de organização das práticas, ações e políticas de saúde que buscam promover a horizontalidade, superando a fragmentação das atividades no interior das unidades de saúde, assim como a percepção dos sujeitos, usuários do sistema, como seres integrais (MATTOS, 2006). Em se tratando de saúde do homem, a integralidade está entre as diretrizes da PNAISH (BRASIL, 2008), prevendo o trânsito do usuário por todos os níveis da atenção, e o respeito à pluralidade dos modos de vida e da situação social do indivíduo.

Schraiber e Figueiredo (2011) articulam a noção de integralidade às discussões de gênero ao apontarem as reduções a que são submetidos os homens em nossa sociedade, e seus reflexos nos serviços. As representações culturais de força e vigor, associadas ao trabalho, e a centralidade da sexualidade como conquista, contrastam com as noções construídas sobre o feminino, que se inscreve no campo da reprodução, do controle da sexualidade e da disciplina e cuidado. Essas reduções não contribuem para uma perspectiva de integralidade em saúde.

\section{Metodologia de pesquisa}

O presente estudo integra uma pesquisa maior sobre os cuidados masculinos voltados para a saúde sexual, a reprodução e a paternidade (GOMES, 2013), aprovada por comitê de ética sob o parecer de número 440.915. Nessa pesquisa, foram utilizados métodos quantitativos e qualitativos. Em termos de abordagem qualitativa, foram utilizadas observações participantes e entrevistas semiestruturadas em três municípios de três regiōes (Nordeste, Sudeste e Sul). Neste estudo, são exploradas 
as entrevistas com homens usuários dos serviços de saúde. As observações foram levadas em conta apenas para contextualizar as entrevistas.

Esses municípios foram selecionados a partir de uma avaliação de um conjunto de experiências consideradas exitosas por gestores de saúde dos estados por meio de consulta eletrônica. Em duas cidades, as ações investigadas se voltavam para o pré-natal; na terceira, o foco era a promoção do cuidado masculino em geral.

Ao todo, foram entrevistados 17 homens: sete da Região Nordeste, quatro da Região Sudeste e seis da Região Sul, com idades entre os 23 e 67 anos. Treze deles tinham ensino fundamental ou médio, dois deles, curso superior completo e dois eram analfabetos. Todos estavam em uma relação estável, formal ou não. Com exceção de um homem, que aguardava a chegada do primeiro filho, todos os outros já tinham filhos. Entre os dados de identificação dos usuários, interessavanos o estado civil, escolaridade, religiosidade, cor de pele, classificação econômica/ renda e escolaridade, aspectos fundamentais para a compreendermos quem eram nossos sujeitos, aqui codificados por nome da região e números sucessivos.

$\mathrm{O}$ roteiro de entrevista visou obter a opinião dos sujeitos sobre o que seria um bom atendimento para os homens adultos, que tivesse como foco a sexualidade, o pré-natal e a paternidade, e o que deveria ser abordado. Com relação ao programa/ ação pesquisados, os sujeitos foram convidados a falar sobre como o conheceram, os motivos de sua procura, há quanto tempo participavam, sua opinião sobre o atendimento, e o que consideravam positivo, negativo ou passível de modificação ou melhoria no programa/ação.

No Nordeste, os informantes foram selecionados de modo aleatório, a partir dos usuários que foram à unidade no dia da ação de saúde. No Sul e Sudeste, também houve seleção aleatória, convidando usuários que estavam com suas companheiras que aguardavam a consulta do pré-natal, mas a maior parte dos informantes foi convidada pela equipe de saúde por já participarem dos programas e açôes que envolviam homens nesses municípios.

Para a análise dos dados, assumimos a matriz hermenêutica-dialética (MINAYO, 2006; GOMES, 1994). Nessa proposta, as falas devem ser compreendidas como parte do contexto em que são produzidas, fazendo parte de sua totalidade; a interpretação desses dados deve também considerar aspectos e condições extradiscursivas. A análise se realiza a partir de níveis de interpretação, e os dados são previamente organizados em passos que possibilitam 
a operacionalização da análise, a partir de quatro aspectos: 1) o atendimento sobre sexualidade, pré-natal e paternidade; 2) seleção dos trechos das entrevistas em que os sujeitos discorriam sobre esses aspectos; 3) síntese interpretativa de cada aspecto, considerando todas as falas; e 4) síntese interpretativa que incluiu todos os dados e aspectos. Como resultados dessas sínteses, elegemos os temas que compóem as seçôes deste artigo.

\section{Considerações iniciais sobre as ações investigadas}

Nos três municípios, as unidades de atenção primária são os cenários de realização das ações voltadas para a saúde masculina e a paternidade, com formas distintas para atrair, incluir e cuidar dos homens.

No Sul, a estratégia empregada foi o Pré-natal Masculino, uma ação desenvolvida desde 2011 e que aposta na inclusão dos homens a partir do pré-natal das parceiras, com o convite a participarem das consultas e realizarem alguns exames laboratoriais. Nessa estratégia, há uma grande preocupação com a saúde da mãe e do bebê, mas o protocolo de atendimento revela que não há o mesmo cuidado quando se trata de exames específicos voltados para os homens, como o PSA, quando eles têm idade superior a 40 anos. A inclusão desse e de outros exames revela que a inserção homem na atenção primária ocorre, a princípio, como pai, mas que ele ganha algum status de sujeito de direito em saúde.

No Sudeste, a inserção dos homens se dá de duas formas: através de uma ação chamada de Pré-natal do Parceiro, desenvolvida desde 2011, e do programa de planejamento reprodutivo, desenvolvido desde a publicação da Lei $n^{\circ}$ 9.263, de 1996, que trata desse tema. Na primeira, os homens são atendidos juntamente com suas companheiras por um(a) ginecologista, exercendo uma função instrumental na promoção do cuidado da mãe e do bebê. Embora o homem também passe pela pesagem e aferição da pressão arterial, os exames solicitados a ele são basicamente os sorológicos para identificação de doenças que podem prejudicar essa díade. Com relação ao planejamento reprodutivo, a inserção ocorre quando o casal decide realizar a vasectomia, cirurgia garantida pela referida lei, e procura o serviço já com essa decisão tomada. Assim como a ação realizada na região Sul, valoriza-se a ideia de um curto período de permanência dos homens no sistema, pois a média de tempo entre o começo do processo 
e a realização da cirurgia varia em torno de 90 dias. Portanto, finalizado o processo, os homens poderão estar outra vez fora do sistema.

No Nordeste, são os homens exclusivamente os alvos e os sujeitos da ação cujo nome associa masculinidade e força, desenvolvida para atrair, inserir e cuidar dos homens na atenção primária. Diferente das citadas anteriormente, essa ação acontece em uma única unidade de saúde, a maior e mais central, geograficamente falando, e em dois dias do mês: um sábado e uma segunda-feira. Por essa peculiaridade, é fundamental a ação dos agentes comunitários de saúde na mobilização dos homens para esse dia específico, quando eles farão coleta de sangue para os exames laboratoriais, consulta médica e participarão de uma roda de conversa sobre temas variados. Por não estar vinculada ao pré-natal ou ao planejamento reprodutivo, a volta desse homem ao serviço dependerá fortemente do vínculo estabelecido com os profissionais, sobretudo com o médico generalista que $\mathrm{o}$ atende. E terá fundamental importância para a sua permanência a mudança de percepção sobre o autocuidado, o que inclui a flexibilização das concepções de gênero. Esse aspecto é também condição para a permanência dos homens no sistema de saúde nos outros dois municípios.

A prevenção como uma ideia e uma prática ainda é estranha aos homens. De modo geral, os entrevistados foram receptivos à ideia da prevenção e promoção da saúde masculina, destacando que os homens não costumam cuidar da saúde.

O homem não está muito preocupado com a saúde dele. Ele vai no médico no último caso quando tá morrendo. Eu achei muito bom continuar isso [refere-se à promoção da paternidade participativa] (Sudeste/1).

Mas também percebemos que eles têm um repertório muito pobre sobre promoção de saúde e autocuidado. Mesmo quando perguntamos sobre suas percepçôes acerca da promoção da saúde masculina de modo geral, sem tocarmos no tema da sexualidade, surgiram preocupaçôes acerca desse tema: o medo do câncer de próstata, da disfunção erétil e das DSTs, sem que houvesse menção a aspectos da saúde masculina em geral.

Ainda que fossem citados aspectos relacionados à sexualidade, os informantes não estabeleceram uma relação direta entre a procura dos serviços de saúde e a prevenção de DST/Aids. Ao que parece, há uma "inaptidão masculina” para as consultas que tenham como finalidade a prevenção, mesmo quando reconhecem que precisam de assistência e cuidado (GOMES, 2008; SCHRAIBER; GOMES; 
COUTO, 2005). A busca pela cura seria uma marca dos depoimentos, em oposição à busca pela prevenção, daí a baixa frequência masculina nas unidades básicas de saúde. Isso fica claro nos trechos a seguir:

Quando ela [a pessoa] vem procurar [atendimento], talvez seja mais fácil porque já chega e diz: ah, estou com isso, e quero resolver isso, o que eu faço? É bem mais fácil do que num dia como hoje [de ação de prevenção], por exemplo. É bem mais fácil você chegar com o problema já. (Nordeste/1)

$\mathrm{O}$ anúncio de um futuro ato sexual - que estaria contido na fala sobre prevenção quando se trata de sexualidade - não é um problema para os homens em nossa cultura, muito pelo contrário (OLIVARRÍA, 1999; PAIVA, 1996; CARRARA, 1996). Então, nos resta presumir que a dificuldade aqui é da própria conversa sobre sexualidade, de falar de sentimentos relacionados ao ato sexual, além da dificuldade de pensar no cuidado preventivo. Além disso, pode haver um desconhecimento sobre o próprio funcionamento do sistema de saúde e sobre as unidades de atenção primária serem também possíveis espaços de prevenção e educação em saúde. Como aponta Schraiber, nesse nível de atenção, ao contrário de os homens serem considerados os personagens principais, a eles são dirigidos os cuidados curativos, com pouca inclusão em açôes educativas ou comunitárias, com exceção dos programas de controle e prevenção de DST e Aids (SCHRAIBER, 2005).

Prevalece a ideia central de "resolver o problema" ou "ficar bom logo", colocando a ênfase na ação curativa e não na prevenção. Realidade que tem íntima relação com as atribuiçôes destinadas socialmente aos homens: serem trabalhadores e provedores da família. Essas normas atravessam e organizam as práticas da assistência, corroboram na construção da ideia de uma restituição rápida da força física masculina, a sua força de trabalho. Eis mais uma mola na articulação que leva os homens a procurarem muito mais os serviços de emergência e hospitais do que de prevenção (SCHRAIBER; FIGUEIREDO, 2001).

Outra questão que parece despontar na fala desses sujeitos é a despreocupação masculina com a saúde sexual e reprodutiva e com o cuidado com o engravidamento. Comportamento respaldado pela nossa cultura que, contraditoriamente, incentiva os homens desde muito cedo a serem ativos sexualmente, enquanto impõe às mulheres, desde a puberdade, as preocupações com a gravidez e o planejamento reprodutivo (HEILBORN; GOUVEIA, 1999; CABRAL, 2003; CARRARA; FARO; RUSSO, 2009; PENAFORTE et al., 2010). A preocupação recai de forma 
mais importante sobre a saúde sexual e a vivência da sexualidade do que sobre a

saúde reprodutiva, incluído aqui o planejamento reprodutivo. Para os homens, a saúde sexual seria um bom motivo para procurar a assistência, embora não falem em prevenção. Assinalamos que, no momento em que os homens procuram os serviços para a cura, os profissionais de saúde teriam uma boa oportunidade de incluí-los em outros programas e ações, atendendo à noção de integralidade.

Quando falamos de saúde do homem, a ideia que surge inicialmente, pelo menos no senso comum, é mesmo relacionada ao sistema reprodutor, mais especificamente à prevenção do câncer de próstata. Nossos informantes também apontaram as doenças da próstata - que, por sua vez, têm estreita relação com a vivência da sexualidade - como motivos para a procura aos serviços, uma vez que o tratamento do câncer prostático pode provocar a disfunção erétil, apontada pelos informantes como uma preocupação. Sem desconsiderar a preocupação real masculina, o tema ganhou ênfase nos últimos anos com o aumento da expectativa de vida da população e, sobretudo, após o lançamento dos medicamentos para disfunção erétil, notadamente o Viagra, em 1998, que intensificou as campanhas médicas e publicitárias de prevenção ao que antes era chamado de impotência sexual (MAKSUD; BRIGEIRO, 1999). Nesse sentido, nas falas, a urologia surge com a especialidade masculina, a clínica do homem, algo que se assemelha à ginecologia para as mulheres, reduzindo a atenção à saúde de homens.

Carrara, Russo e Faro (2009) chamam a atenção para esse fato e criticam a centralidade da próstata, ou do câncer de próstata, como um perigo letal e eminente à saúde masculina, quando, na verdade, há causas mais relevantes de mortalidade. Ainda segundo os autores, sendo a ideia de potência e de invulnerabilidade relacionadas à masculinidade hegemônica, consideradas historicamente como entraves à promoção de saúde dos homens, a ênfase na próstata e na potência masculina como sinal de saúde parece tomar o caminho oposto do esperado, ou seja, reforçar valores que deveriam ser abandonados em prol da saúde masculina.

\section{As dissonâncias entre a saúde masculina, saúde sexual e planejamento reprodutivo}

Com relação à saúde sexual e reprodutiva, apesar das mudanças que vêm se apresentando nos últimos anos no universo masculino, sobretudo nas camadas médias (RIBEIRO, 2011), historicamente, o planejamento reprodutivo é uma 
atribuição feminina, enquanto os homens, não raramente, tendem a escapar dessa responsabilidade (CARRARA; FARO; RUSSO, 2009; PENAFORTE et al., 2010). Uma realidade vivenciada também em outras culturas, como apontam pesquisas recentes (KABAGENYI et al., 2014; GERRITSEN, 2009).

Em se tratando do princípio da integralidade e as ações investigadas aqui, lembramos que as açóes voltadas para o cuidado do homem/pai vêm sendo desenvolvidas no âmbito de programas de planejamento reprodutivo e, mais recentemente, do pré-natal. Ações que, do ponto de vista social e biológico, não têm o homem como foco central, mas a mulher e a criança.

Sobre as cirurgias de esterilização de homens e mulheres, Berquó e Cavenaghi (2003) apontam que a esterilização feminina voluntária tem sido uma prática comum de controle da fecundidade no Brasil. Por outro lado, a esterilização masculina - vasectomia-era menos praticada do que outros métodos tradicionais, como a abstinência periódica e o coito interrompido. Embora fosse menos frequente e proibida como prática de esterilização antes de 1997, ela já figurava como um procedimento pago pelo SUS desde 1992, o que não acontecia com a esterilização feminina. Dados da PNDS-1996 mostram ainda que, dos homens casados ou unidos, apenas $2,4 \%$ estavam vasectomizados, enquanto que $40,3 \%$ tinham esposas já esterilizadas, e que a esterilização feminina era mais conhecida pelos homens $(87,7 \%)$ do que a própria vasectomia (72,3\%). Esses dados levam as autoras a afirmar que a "prevalência da laqueadura tubária e da vasectomia são eloquentes quanto ao papel que tem cabido às mulheres, em especial às unidas, no sentido da regulação da fecundidade e do controle definitivo da reprodução" (BERQUÓ;CAVENAGHI, 2003,p.S449), aspectos que também percebemos em nossa pesquisa, como mostraremos a seguir.

Entre os entrevistados do Sudeste, a cirurgia de vasectomia apareceu como o principal motivo para buscarem os serviços de saúde, sobretudo na atenção primária, nível indicado para esses programas, como regulamenta a Lei. Segundo uma gestora, o número dessas cirurgias vem aumentando a cada ano no seu município. Mas é interessante notar que os informantes não se referiram ao planejamento reprodutivo propriamente dito, mas à cirurgia. A presença masculina acontece quando o casal já decidiu pela vasectomia e recorre ao sistema público de saúde para a sua realização. Se a decisão não for pela cirurgia de vasectomia, 
os homens não acessarão o sistema pela via desse programa de planejamento reprodutivo, uma vez que essa é considerada uma atribuição feminina:

Isso aconteceu [a procura pela cirurgia] porque a minha esposa teve uma gravidez de risco. Falaram que a cirurgia que eu ia fazer era mais simples e, como eu nunca fiz nenhuma cirurgia, achei melhor optar pela vasectomia. (Sudeste/2)

Eu procurei [a vasectomia] porque minha mulher não pode mais ter filhos. Ela já se submeteu a duas cirurgias e as recomendações médicas dizem que ela corre risco de morte se ela tiver uma nova gravidez. (Sudeste/3)

O que está implícito é que a vasectomia é uma alternativa quando: há uma impossibilidade para a realização da laqueadura das trompas; a mulher não pode mais engravidar e, ao mesmo tempo, não pode fazer uso de contraceptivos hormonais. As primeiras opções são sempre os métodos que incidem sobre o corpo da mulher. Em se tratando da busca pela integralidade, esses homens parecem incorporar o que o sistema lhes oferece: programas e ações de saúde estanques. $\mathrm{O}$ planejamento, mesmo nesse município, que tem um programa há muitos anos, ainda não oportuniza plenamente a inserção dos homens nos serviços.

Tomando esse exemplo, é interessante perceber que programas de planejamento reprodutivo tendem a ser organizados pelas coordenações e secretarias de saúde da mulher. Trata-se de uma opção política e institucional que contribui para a reafirmação de que é o corpo da mulher o alvo das ações e cuidados quando se trata do planejamento, engravidamento, métodos contraceptivos etc. Também deve ser dela a preocupação sobre esses temas, que podem ser discutidos com ginecologistas desde a primeira consulta da adolescente ou durante o pré-natal. Um desdobramento político que também pode ser apontado como um entrave à inclusão dos homens no planejamento reprodutivo (KABAGENYI et al., 2014; GERRITSEN; DEVILLÉ, 2009).

Os depoimentos apontam para uma satisfação em relação à oferta da cirurgia pelo SUS e com o serviço oferecido pelo município. O processo para se chegar a fazer a cirurgia segue regras estabelecidas pela Lei, que incluem palestras de esclarecimento e aconselhamento sobre a cirurgia, consultas pré e pós-cirúrgicas e exames laboratoriais. Nesse processo, o tema da sexualidade está sempre presente, e o medo da disfunção erétil pós-cirúrgica é um receio que atravessa a percepção e os discursos desses usuários quando o tema é a cirurgia. Mas é importante ressaltar que os homens que aguardavam a cirurgia de vasectomia não 
mencionaram que haviam passado por uma consulta médica mais abrangente. Da mesma forma, as conversas sobre sexualidade resumiram-se às explicações sobre a relação entre a cirurgia e o desejo sexual e a função erétil. E os homens reconhecem que a abordagem é falha:

Vim aqui pra ser orientado com relação ao procedimento da vasectomia. Não me foi perguntado se eu tenho algum outro problema de saúde. Tratar de uma forma mais ampla da saúde do homem, talvez isso não tenha ocorrido (Sudeste/3).

Com relação a essa fala, faz-se necessário refletir sobre a noção de integralidade e as questões de gênero e sexualidade masculinas. O que se explicita é que a consulta para habilitação para a cirurgia de vasectomia poderia ser uma chance de ampliar a investigação sobre a saúde dos usuários, mas isso se perde quando esta é reduzida aos esclarecimentos sobre a própria cirurgia e seus reflexos sobre a sexualidade desse homem. Perde-se, portanto, a possibilidade de articulação com outros programas já existentes no sistema de saúde, cujo foco é a prevenção de inúmeras doenças que acometem e matam mais, inclusive, do que o tão referido câncer de próstata, como os programas antitabagistas ou de prevenção e controle da hipertensão e diabetes. Configura-se ainda como uma fissura entre os gêneros no plano das ações de saúde, desconsiderando a possibilidade de uma articulação mais profunda entre políticas e ações que têm homens e mulheres como focos principais, mas que não devem ser fragmentadas por sexo, ferindo a noção de integralidade em saúde.

De modo geral, entre as ações investigadas, ficou evidente que elas não estabeleciam relação com outras ações ou programas. Nas ações do Sudeste, não observamos a articulação entre planejamento reprodutivo e a promoção da paternidade cuidadora. Nos serviços do Sul e do Nordeste, não observamos ações que tenham a saúde sexual e reprodutiva como focos.

Em se tratando de gênero e sexualidade, a ideia é a preservação da função erétil e penetrativa. As outras questões da sexualidade não são passíveis de serem conversadas numa consulta médica que tem como finalidade a habilitação para a cirurgia de vasectomia. Uma redução da sexualidade masculina à penetração, ou à norma anatômico-fisiológica da ereção (ROHDEN, 2009), que ganhou novos contornos com o advento do Viagra (ROHDEN, 2009; CARRARA; FARO; RUSSO, 2009; GIAMI, 2009). Nesse sentido, trata-se também de desconsiderar a noção de integralidade em saúde. 
Saúde do homem, pré-natal e paternidade:

uma relação que ainda não se estabeleceu

Em nossa sociedade, há uma supervalorização da maternidade em detrimento da paternidade (BADINTER, 1985; TONELI et al, 2011; FREIRE, 2011). Essa valorização tem os seus primeiros sinais no século XIX, mas pode ser percebida ainda hoje nas famílias e no sistema de saúde. $\mathrm{O}$ argumento principal é que as mulheres são "naturalmente" propensas ao cuidado com os filhos, uma vez que seus corpos são construídos para a gestação e amamentação. Já os homens fogem desse "destino natural" também por conta do seu corpo, que não gera, não dá a luz ou amamenta. Uma adaptação do social ao natural que parece ser quase automática no senso comum e que afasta os homens dos cuidados com os filhos.

Nos serviços investigados no Sudeste e no Sul, as ações de promoção de saúde do homem surgiram articuladas ao pré-natal: "pré-natal masculino" e "pré-natal do parceiro". Apesar dos títulos, que incluem as palavras "parceiro" e "masculino", percebe-se que os cuidados com a díade mãe-bebê são os focos principais dessas ações, enquanto o homem-pai ocupa o papel auxiliar na promoção da saúde do referido par e de coadjuvante em uma ação que leva seu nome.

O reforço dessa posição de auxiliar reservada aos homens-pais vem ainda da evidenciação de que o envolvimento com a paternidade e o cuidado com os filhos desde o pré-natal influencia fortemente a saúde física e psicológica da criança e da mulher/mãe, além de reduzir os índices de violência doméstica (BRANCO, 2014). Reflexo da ideia de necessária proteção com o binômio mãe-filho, que vem se desenvolvendo desde o século XIX e se intensificando no século seguinte, espraiando-se pela sociedade de modo geral e pela saúde (FREIRE, 2011).

Além disso, a promoção da saúde do homem e a presença masculina nas unidades básicas de saúde ainda são novidades, requerendo novas reflexões, repertórios, construções de fluxos e linhas de cuidado que alavanquem a inclusão dos homens no sistema (GOMES et al., 2012). A mãe e o bebê são considerados as partes frágeis e vulneráveis do conjunto, em oposição aos homens. São essas percepções, permeadas pela nossa cultura de gênero, que vêm impedindo os profissionais de saúde - e os próprios homens - de se perceberem como sujeitos de direito em saúde. $\mathrm{O}$ resultado são ações voltadas para a paternidade que não conseguem incluir verdadeiramente os homens nas ações de saúde em geral, e se articular com ações que historicamente têm as mulheres e as crianças como alvos da atenção. 
Do ponto de vista da saúde masculina propriamente dita, o que poderíamos esperar é que, ao participarem do pré-natal, esses homens fossem convidados a tomar parte em ações mais amplas e não pontuais. O que se explicita é a preocupação com a mãe e o bebê:

Fala pré-natal, mas são simples exames. Mas é bom porque geralmente os homens não vêm no médico. Foi isso, lembro que foi isso. (Sudeste/2)

Uma coisa que é voltada para o homem também [sobre a ação voltada para a paternidade]. É pedido exames dela e também é pedido meus exames. Exame de sangue pra ver se tem algum tipo de doença. Tudo isso voltado para a criança (Sudeste/1)

No trecho a seguir, esse mesmo homem que achou a ação interessante e válida, afirma desejar ampliar seus conhecimentos com relação ao cuidado com o bebê que vai nascer e espera isso do serviço de saúde, uma vez que está inserido numa ação de valorização da paternidade. No entanto, esse tipo de ensinamento não está previsto nas ações do serviço estudado:

Eu espero aprender a cuidar da criança do mesmo modo que a minha companheira vai aprender a cuidar. Dar banho, esse tipo de coisa. Mas eu não sei se futuramente as enfermeiras vão me ensinar cuidar do meu filho, trocar fralda, esse tipo de coisa, e eu espero isso (Sudeste/1).

Mas as açôes vêm se desenvolvendo de formas distintas. No serviço do Sul, esses exames vão além dos testes sorológicos a que são submetidas também as mulheres grávidas para detecção de DSTs e Aids, e incluem exames como índice glicêmico, colesterol e PSA para detecção de males que não interferem diretamente na saúde da referida díade:

Nunca tinha vindo no Posto. Eu tinha medo de injeção. Teve uma empresa que pediu o exame sanguíneo, mas eu falei: então você me demita que eu não vou fazer exame! Foi o neném que me obrigou. Esse bebê está fazendo milagre! Foi bom, pois eu fiz todos os exames, fiz da próstata (Sul/1).

Eu acho que quando a mulher está grávida o homem também está grávido. Então tem que cuidar da saúde dele, do filho, da mulher, dos três juntos (Sul/2)

Eu acho que eles não se preocupavam tanto com o pai. Na primeira (gravidez), eles (equipe médica) faziam pergunta só pra minha esposa. E agora, nessa, eles até faziam perguntas pra mim, principalmente o médico e a enfermeira. Eu acho que teria que perguntar também pro marido. Fazer ele sentir que faz parte daquilo (Sul/3).

Um dos depoimentos evidencia a resistência dos profissionais médicos na adoção de uma nova postura diante do homem/pai no momento do pré-natal 
(CARVALHO, 2003), e deixa clara a diferença que faz a inclusão da enfermeira na consulta, apontando para uma postura mais ativa:

Hoje é a segunda vez que eu estou entrando no consultório. Na primeira vez não foi pedido esse exame porque na primeira vez ela [a enfermeira obstétrica] não estava. Só estava o doutor. O médico não pediu [o exame], foi a enfermeira. (Sul/4)

Para alguns homens, essa ação foi a primeira oportunidade em muitos anos de realizaram exames clínicos e laboratoriais, e eles valorizam isso. Percebem ainda a mudança no tratamento dispensado a eles por médicos(as) e enfermeiros(as) nas consultas de pré-natal, o que revela também mudanças no comportamento dos trabalhadores da saúde. No entanto, a última fala permite-nos pensar que ainda são os(as) médicos(as) os(as) mais resistentes à inclusão dos homens no pré-natal, parto e pós-parto (CARVALHO, 2003).

Destacamos que os homens entrevistados não participavam de programas de planejamento reprodutivo, nem sequer sabiam se havia um programa no município. E revelaram que a equipe de saúde, ou o(a) médico(a) ou enfermeiro(a) que vinha acompanhando a sua esposa e a ele no pré-natal não havia conversado sobre planejamento.

Por fim, os homens queixaram-se da pouca divulgação e visibilidade das ações de pré-natal masculino.

Não sabia [sobre a ação]. Eu acho que falta um pouco mais de propaganda. Sempre tem mulher, câncer de mama, isso e aquilo, e não tem, e homem? Não tem uma coisa que leve ele ao Posto de Saúde aqui, que diga "vá lá que está esperando você lá”. Não existe isso na mídia $(\mathrm{Sul} / 1)$

Esse dado parece revelar que, nesse aspecto, também há uma disparidade entre a atenção conferida à promoção da saúde da mulher e da criança e a atenção à saúde dos homens. Além da disparidade entre a divulgação de ações para os dois sexos na mídia, também não há divulgação em forma de cartazes ou panfletos nas unidades de saúde dos municípios que desenvolvem ações de pré-natal do parceiro.

\section{Considerações finais}

Apesar de acreditarem ser importante uma maior inclusão dos homens nos serviços de saúde, nossos sujeitos apontaram como impeditivos dessa presença o papel de provedor da família e o medo de perderem o trabalho ou fragilizarem 
a relações com a chefia. Atuarem de forma autônoma no mercado de trabalho apareceu como uma variante dessa questão: serem autônomos ou estarem inseridos informalmente no mercado de trabalho significa terem ganhos diários, e não mensais, dificultando a ida aos serviços. O longo tempo de espera pelo atendimento; a pouca resolutividade dos serviços, que os obriga a voltar outras vezes, perdendo outros dias de trabalho; e a ideia recorrente de que os homens são mesmo mais descuidados com a saúde são aspectos presentes nos discursos dos nossos sujeitos das três regiōes. Houve defesa ou reforço dessa ideia, mas eles se mostraram cientes de que ela existe em nossa cultura e é um impeditivo ao acesso dos homens. Todos esses são aspectos que já vêm sendo apontados pela literatura (GOMES, 2008; MEDRADO; LYRA; AZEVEDO, 2011).

A nosso ver, o pré-natal, o planejamento reprodutivo e a promoção da saúde do homem seriam ações que "naturalmente conversariam" na atenção básica, mas isso não foi observado. Portanto, podemos dizer que a noção de integralidade não vem sendo contemplada nas ações investigadas: quando existe um programa de planejamento reprodutivo, não existe um programa em que o homem-pai seja percebido como sujeito de cuidado e de direito em saúde. E quando existe um programa em que o homem-pai é assistido em suas necessidades básicas de saúde durante o pré-natal, não existe um programa de planejamento reprodutivo. Em ambos os casos, o homem está presente mais como auxiliar no cuidado e promoção da saúde da díade mãe-bebê do que como sujeito de direito em saúde.

Assim, a referida promoção da paternidade cuidadora está presente somente no que diz respeito ao cuidado que esse homem deve ter com a saúde da mãe e da criança que está sendo gestada, estando ausente a ideia de promoção de uma paternidade prazerosa e mais igualitária, se comparada com a promoção da maternidade. O "nascimento" desse pai se dará pela responsabilidade, não pelo prazer ou pela promoção de uma paternidade que tenha o mesmo peso e valor da maternidade (RIBEIRO; GOMES; MOREIRA, 2015).

Acreditamos que é preciso provocar a percepção dos usuários e dos profissionais sobre a necessidade de inserção dos homens no sistema como sujeitos de direitos em saúde. Feito isso, o vínculo com esses homens poderá ser estendido para além do período da gravidez e da realização da vasectomia. ${ }^{1}$ 


\section{Referências}

BADINTER, Elisabeth. Um amor conquistado: o mito do amor materno. Rio de Janeiro: Nova Fronteira, 1985.

BRANCO, V. C. Profissionais de saúde - parceiros na construção de uma sociedade mais solidária. Unidade de Saúde Parceira do Pai. Rio de Janeiro: Secretaria Municipal de Saúde, 2014.

BRASIL. Secretaria de Atenção à Saúde. Departamento de Ações Programáticas Estratégicas. Política Nacional de Atenção Integral à Saúde do Homem. Brasília, 2008.

BERQUÓ, E.; CAVENAGHI, S. Direitos reprodutivos de mulheres e homens face à nova legislação brasileira sobre esterilização voluntária. Cadernos de Saúde Pública, Rio de Janeiro, v. 19, sup. 2, p. S441-S453, 2003.

BRIGEIRO, M.; MAKSUD, I. Aparição do Viagra na cena pública brasileira: discursos sobre pública brasileira: discursos sobre corpo, corpo, gênero e sexualidade na mídia. Estudos Feministas, Florianópolis, v. 17, n. 1, p. 296, jan.-abr. 2009.

CABRAL, C. S. Contracepção e gravidez na adolescência na perspectiva de jovens pais de uma comunidade favelada do Rio de Janeiro. Cadernos de Saúde Pública, Rio de Janeiro, v. 19, sup. 2, p. S283-S292, 2003.

CARRARA, S. Tributo a Vênus: a luta contra a sífilis no Brasil, da passagem do século aos anos 40. Rio de Janeiro: Fiocruz, 1996.

CARRARA, S.; RUSSO, J. A.; FARO, L. A política de atenção à saúde do homem no Brasil: os paradoxos da medicalização do corpo masculino. Physis - Revista de Saúde Coletiva, v. 19, n. 3, p. 658-677, 2009.

CARVALHO, M. L. M. de. Participação dos pais no nascimento em maternidade pública: dificuldades institucionais e motivações dos casais. Cadernos de Saúde Pública, v.19, supl.2, Rio de Janeiro, 2003.

CONNELL, R. Políticas da masculinidade. Revista Educação e Realidade, Porto Alegre, v. 20, n. 2, p. 185-206, jul./dez.1995.

CORREAA, S.; PETCHESKY, R. Direitos Sexuais e Reprodutivos: uma perspectiva feminista. Physis, Revista de Saúde Coletiva, Rio de Janeiro, v. 6, n. 1-2, 147-177, 1996.

CORREA, S.; MESSERSCHMIDT, J. W. Masculinidade hegemônica: repensando o conceito. Estudos Feministas, Santa Catarina, v. 21, n. 1, p. 241-282, 2013.

COUTO, M. T.; GOMES, R. Homens, saúde e políticas públicas: a equidade de gênero em questão. Ciência \& Saúde Coletiva, Rio de Janeiro, v. 17, n. 10, p.2569-2578, out 2012.

FREIRE, M. M de L. Maternalismo e proteção materno-infantil: fenômeno mundial de caráter singular. Cadernos de História da Ciência - Instituto Butantan, v. 7, n. 2, jul/dez 2011. 
GERRITSEN, A., DEVILLÉ, W. L. Gender differences in health and health care utilisation in various ethnic groups in the Netherlands: a cross-sectional study. BMC Public Health, v. 20, n. 9, p. 109, 2009.

GIAMI, Alain. Da impotência à disfunção erétil: destinos da medicalização da sexualidade. Physis - Revista de Saúde Coletiva, Rio de Janeiro, v. 19, n. 3, p. 637-657, 2009.

GOMES, R. A análise de dados em pesquisa qualitativa. In: MINAYO, M. C. de S. Pesquisa Social: teoria, método e criatividade. Petrópolis, RJ: Vozes, 1994.

GOMES, R. et al. Avaliação das Ações Iniciais da Implantação da Política Nacional de Atenção Integral à Saúde do Homem. Relatório Final. Rio de Janeiro: IFF, 2012.

. Sexualidade Masculina, Gênero e Saúde. 1. ed. Rio de Janeiro: Fiocruz, 2008. v. 1. 184p. _. A saúde do homem em foco. São Paulo: Editora UNESP, 2010.

. Os cuidados masculinos voltados para a saúde sexual, a reprodução e a paternidade a partir da perspectiva relacional de gênero. Projeto de Pesquisa. Rio de Janeiro: Instituto Nacional de Saúde da Mulher, da Criança e do Adolescente Fernandes Figueira/Fiocruz, 2013.

GOMES, R. et al. As arranhaduras da masculinidade: uma discussão sobre o toque retal como medida de prevenção do câncer prostático. Ciência \& Saúde Coletiva, Rio de Janeiro, v. 13 , n. 6, nov./dez. 2008.

GOMES, R. et al. Os homens não vêm! Ausência e/ou invisibilidade masculina na atenção primária. Ciência \& Saúde Coletiva, Rio de Janeiro, v. 16, supl. 1, 2011.

HEILBORN, M. L.; GOUVEIA, P. F. "Marido é tudo igual”: mulheres populares e sexualidade no contexto da Aids. In: PARKER, R.; BARBOSA, R. Sexualidades pelo avesso: direitos, identidades e poder. Rio de Janeiro: IMS/UERJ; São Paulo: Ed. 34, 1999. p. 175-198.

KABAGENYI, A. et al. Barriers to male involvement in contraceptive uptake and reproductive health services: a qualitative study of men and women's perceptions in two rural districts in Uganda. Reprod Health, v. 11, n. 1, p. 21, 2014.

KEIJZER, B. Hasta donde el cuerpo aguante: género, cuerpo y salud masculina. In: CÁCERES, C et al. (Org.). La salud como derecho ciudadano: perspectivas y propuestas desde América Latina. Lima: Facultad de Salud Pública y Administración de la Universidad Peruana Cayetano Herida, 2003. p. 137-152.

KIMMEL, M. A produção simultânea de masculinidades hegemônicas e subalternas. Horizontes Antropológicos: Corpo, Doença e Saúde, v. 4, n. 9, p. 103-117, out. 1998.

MATTOS, R. A. Os Sentidos da Integralidade: algumas reflexões acerca de valores que merecem ser defendidos. In: PINHEIRO, R.; MATTOS, R. A. (Org). Os sentidos da integralidade na atenção e no cuidado à saúde. 6. ed. Rio de Janeiro: IMS/UERJ - CEPESC - ABRASCO, 2006. 180p.

MEDRADO, B.; LYRA, J.; AZEVEDO, M. "Eu não sou só próstata, eu sou homem!. Por uma política pública de saúde transformadora da ordem de gênero. In: GOMES, R. (Org). Saúde do Homem em Debate. Rio de Janeiro: Ed. Fiocruz, 2011. 
MINAYO, M. C. de S.O desafio do conhecimento: pesquisa qualitativa em saúde. São Paulo: Editora Hucitec; 2006.

PAIVA, V. Sexualidades adolescentes: escolaridade, gênero e sujeito sexual. In: PARKER, R.; BARBOSA, R. (Org.).Sexualidades brasileiras. Rio de Janeiro: Relume Dumará, 1996. PENAFORTE, M. C. L. F. et al. Conhecimento, uso e escolha dos métodos contraceptivos por um grupo de mulheres de uma unidade básica de saúde em Teresópolis/RJ. Cogitare Enfermagem, v. 15, n. 1, p. 124-130, jan./mar. 2010.

RIBEIRO, C. R. Sexualidade, corpo e saúde masculinos: transformações e permanências nos discursos de homens e da revista Men's Health. 2011. 322 f. Tese (Doutorado) - Instituto de Medicina Social - Universidade do Estado do Rio de Janeiro, Rio de Janeiro. 2011.

RIBEIRO, C. R. GOMES, R.; MOREIRA, M. C. N. A paternidade e a parentalidade como questôes de saúde frente aos rearranjos de gênero. Ciência \& Saúde Coletiva. No prelo, 2015.

ROHDEN, F. Diferenças de gênero e medicalização da sexualidade na criação do diagnóstico das disfunções sexuais. Revista Estudos Feministas, Florianópolis, v. 17, n. 1, p. 89-109, 2009. SCHRAIBER, L. B.; GOMES, R.; COUTO, M. T. Homem e saúde na pauta da saúde coletiva. Ciência \& Saúde Coletiva, v. 10, n. 1, p. 7-17, 2005.

SCHRAIBER, L. Equidade de gênero e saúde: o cotidiano das práticas no Programa Saúde da Família do Recife. In: VILELLA, W.; MONTEIRO, S.(Org.) Gênero e saúde: Programa Saúde da Família em questão. São Paulo: Abrasco; Brasília: UNFPA, p. 39-60, 2005.

SCHRAIBER, L. B.; FIGUEIREDO, W. S. Integralidade em saúde e os homens na perspectiva relacional de gênero. In: GOMES, R. (Org). Saúde do Homem em Destaque, Rio de Janeiro: Editora Fiocruz, p. 11-18, 2011.

SCOTT, J. Gênero: uma categoria útil de análise histórica. Educação e Realidade, v. 20, n. 2, jul./dez. 1995.

SUTTER, C.; BUCHER-MALUSCHKE, J. S. N. F. Pais que cuidam dos filhos: a vivência masculina na paternidade participativa. Psico, Porto Alegre, PUCRS, v. 39, n. 1, p. 74-82, jan./mar. 2008.

TONELI, M. J. F. et al. Paternidades e políticas de saúde no contexto da gravidez na adolescência. In: TONELI, M. J. F. et al. (Org.). O pai está esperando? Políticas Públicas de saúde para a gravidez na adolescência. Florianópolis: Ed. Mulheres, 2011.

\section{Nota}

${ }^{1}$ C.R. Ribeiro participou como pesquisadora na fase de construção de dados; analisou esses dados, utilizados na elaboração do artigo; e participou da redação final. R. Gomes coordenou o projeto que originou o artigo e participou da análise dos dados e da redação final do artigo. M.C.M. Nunes participou como pesquisadora na fase de construção de dados, na análise destes e na redação final do artigo. 
Meetings and disagreements between men's health, the promotion of participatory parenting and sexual and reproductive health in basic care In this article, we discuss three health actions developed in basic health units in three cities of different Brazilian regions, and focused on human health, promoting participatory fatherhood and sexual and reproductive health. It is a qualitative research in which data were built on interviews with 17 men, users of the health system and involved in these actions, and observations. In analyzing the data gender concepts, masculinities and integrality were brought in a special way; as analysis methodology, we used the hermeneutic-dialectic perspective. Among other things, we concluded that men realize that gender issues still constitute impediments to this insertion, as well as the system itself organization; and that actions are organized in tight and piecemeal acting on isolated aspects of health male, not contemplating the principle of integration and hindering the promotion of the relationship of these men to the system for primary health.

> Keywords: men's health; parenthood; sexual and reproductive health; integrality; gender. 